\title{
Autotelic and Instrumental Need for Touch: Searching for and Purchasing Apparel Online
}

\author{
Roberto Manzano $^{1 *}$, Diana Gavilan¹, Magdalena Ferrán², María Avello ${ }^{1}$ and Carmen Abril ${ }^{1}$
}

${ }^{1}$ Department of Marketing and Market Research, Complutense University of Madrid, Spain

${ }^{2}$ Department of Applied Statistics, Complutense University of Madrid, Spain

\begin{abstract}
Apparel is considered to be a category where haptic cues play a key role in evaluating product properties, and yet the consumer buying process in said retail channel is hindered by restricted product experience and evaluation due to the intrinsic absence of haptic options. The current research seeks to gain deeper insights into the knowledge and understanding of consumer autotelic and instrumental need for touch (NFT] in the search and purchase stages of buying apparel online. Using a self-reported questionnaire, data were collected from 227 subjects. Results indicate that consumers high in autotelic NFT and instrumental NFT show a lower likelihood to purchase apparel online. Also a significant moderating effect for utilitarian shopping orientation and instrumental NFT on online apparel search and purchase was also found. These findings have important implications for online retailers since overcoming the lack of NFT remains a major obstacle in the adoption of this channel. In addition, directions for future research are suggested.
\end{abstract}

Keywords: Touch; Sensory marketing; Instrumental need for touch; Autotelic need for touch; Decision process; Shopping orientation; Consumer behavior; Purchasing consumer stages; Online shopping; Apparel retailing

\section{Introduction}

According to eMarketer [1], online sales of apparel and accessories amounted to $\$ 44.7$ billion in 2013 , and are estimated to reach $\$ 86$ billion by 2018. The huge growth of the Internet as a search and purchase channel for apparel poses fresh challenges for the sector. One key challenge in the apparel purchasing process online is that consumers will be reluctant to buy what they can't touch.

Prior research has shown that the relevance of touch and the consumer need for haptic information depends mainly on product category [2-4], on product properties [5], and on the type of material [6].

Apparel is considered to be a category where haptic perception plays an important role in evaluating product properties since the dominant attribute of said category is texture, a feature which conveys qualities such as softness, warmth or flexibility [7]. The shopping experience of apparel has traditionally been studied in the light of the importance attached by consumers to the incoming information provided by all senses, particularly by touch [8].

The study of the importance of individuals' differences in haptic orientation considers need for touch (NFT) as a key element, being defined as "a preference for the extraction and utilization of information obtained through the haptic system" [4-9]. It emerges as a need to obtain information from the physical attributes of the product (Instrumental NFT) as well as pleasurable emotions and enjoyment through direct contact with the products, making touch an end in itself (Autotelic NFT) [9].

Touch plays a diagnostic role for customers shopping at a brickand-mortar retailer, providing objective information relevant to product judgment, increasing confidence in product evaluation and reducing associated risks [10]. In addition to examining product characteristics, the sensations to emerge from touch are also related to strong hedonic experiential content.Therefore, when appraising retail offerings of apparel where product properties are salient characteristics, tactile input become crucial and often lie at the heart of purchase decisions [11].
However, today's landscape is no longer only physical. New online retailers are emerging and traditional retailers are moving into the online channel [12]. Yet, the Internet remains a challenging distribution channel for apparel since clothing is considered to be a high involvement category [13] where there is a strong need for products to be seen, felt, touched [2] and tried on. In fact, this category is still a clear example that perhaps for some consumers, traditional retail shopping may not be easily replaced [6].

Despite efforts to promote the creation of rich and pleasurable shopping experiences of apparel online through compensational strategies such as written descriptions and pictures [14], there are still many gaps and unanswered questions concerning the impact of the lack of touch in the information search and purchase stages of apparel in the online channel.

Since information search has shown to be the most important functional element leading to purchase via the Internet [15], the purpose of this research is to better understand the following questions. Does the absence of touch in online channel equally influence the search and the purchasing stages of the apparel purchasing? Is this barrier equally important for consumers high vs. low in both autotelic and instrumental NFT? Given that there are consumers with different shopping orientations (hedonic and utilitarian) [16], how do such shopping orientations interact with consumers' autotelic and instrumental NFT?

Based on the previous questions, the current research seeks to gain deeper insights into knowledge and understanding of NFT in the apparel search and purchase stages of the buying process in an online environment. First, the influence of consumer NFT (autotelic instrumental) in the use of the online channel for apparel information

${ }^{*}$ Corresponding author: Roberto Manzano, Department of Marketing and Market Research, Complutense University of Madrid, Spain, Tel: 0034619778107/91 394 6744; E-mail: rmanzano@ccee.ucm.es

Received February 11, 2016; Accepted February 18, 2016; Published February 22, 2016

Citation: Manzano R, Gavilan D, Ferrán M, Avello M, Abril C (2016) Autotelic and Instrumental Need for Touch: Searching for and Purchasing Apparel Online. Int $J$ Econ Manag Sci 5: 322. doi:10.4172/2162-6359.1000322

Copyright: (c) 2016 Manzano R, et al. This is an open-access article distributed under the terms of the Creative Commons Attribution License, which permits unrestricted use, distribution, and reproduction in any medium, provided the original author and source are credited. 
search and purchase is explored. Second, the moderating effect of the shopping orientations, hedonic vs utilitarian, on the previous relationship is analyzed as seen from Figure 1.

The paper is organized as follows. The background literature on the need for touch, online consumer behavior, and shopping orientation is first reviewed, and the proposed hypotheses are then set out. Second, a description of the research methodology and results is provided. Third, the main results are reported. The final sections include the main conclusions, the contributions and implications of the research and suggest potentially fruitful topics for future research in this area.

\section{Theoretical Background and Hypotheses}

\section{Need for Touch (NFT) and its instrumental and autotelic dimensions}

Research focused on the importance of individuals' differences in haptic orientation has found that the need for touch (NFT) is a psychological trait defined as "a preference for the extraction and utilization of information obtained through the haptic system" [4,9].

Interest in haptic information can be autotelic in nature, which means that it is not connected directly with the purchase decision. In this situation, haptic information includes elements related to the pleasure and enjoyment the consumer feels through direct contact with the products, thus making touch an end in itself [9]. On the other hand, instrumental NFT refers to the information obtained from the physical attributes of the product as well as the confidence and security derived from touch, whether concerning geometric variables such as size or shape, or material attributes such as texture, hardness, weight or temperature [5].

NFT conceptualization allows consumers to be classified both on an overall level (high/low NFT), and for each of the dimensions, i.e., autotelic or instrumental. Consumers high in NFT show differences vs. those low in NFT in the use of touch as a means of gathering information. High NFT consumers display a greater ability to access haptic information, evidence a faster memory with regard to tactile items, and use touch at an early stage in their product evaluation [4]. Equally, high levels of NFT influence consumer's perception of the product, thus generating greater confidence and less frustration if they have direct access to it [9]. The level of NFT also affects elements such as speed of access to tactile information [4], motivation and skill in processing written messages [9], consumer assessment and trust, as well as appraisal of product quality $[3,4]$.

\section{Need For Touch [NFT] in apparel online shopping at the search and purchase stages of the decision process}

In the clothing and textile category, touch is very relevant as it plays a dual role in evaluating the physical attributes of the product such as

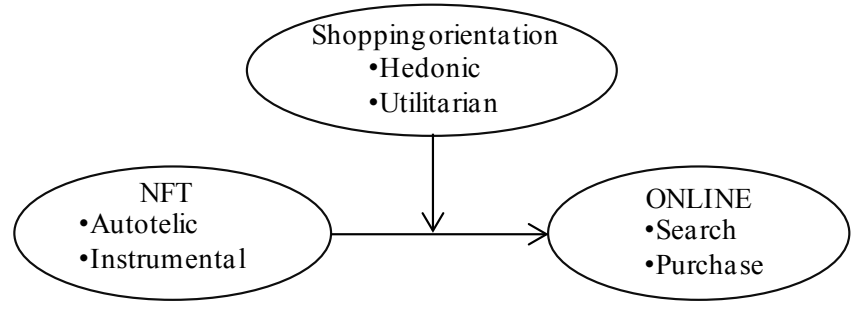

Figure 1: Conceptual Framework. texture $[3,5]$ whilst also evaluating the sensations aroused related to a strong experiential content [17].

Expanding into online sales in the fashion sector offers a wealth of opportunities as retailers can better meet consumer needs by enhancing the benefits and avoiding the weaknesses of the brick and mortar channel, e.g. access to new markets without the need to invest in buildings and personnel, or the 24/7 availability of the online channel $[18,19]$. Nevertheless, online channels are yet to overcome certain barriers such as better retailer understanding of its dynamics and specifically the lack of touch, which is essential in products like clothing [20].

Consumers go through a number of different stages during their buying process. Among these, need for touch might prove relevant at two phases: pre-purchase or information search stage, and purchase stage [21]. Research has shown that consumers exhibit different behaviors during these stages.

During the pre-purchase stage, consumers primarily seek information concerning the features of the products they are considering purchasing and familiarize themselves with what is on offer. At this stage, the available information allows consumers to assess the attributes and quality of the product as well as compare various alternatives in order to facilitate a subsequent decision, making the purchase more likely $[2,22]$.

The literature suggests a wide range of haptic and non-haptic compensational strategies to overcome the lack of touch during the search stage, such as special offers, written descriptions or even virtual apps. Haptic compensation tactics include informing the consumer of the product's characteristics in tactile terms [6], providing a picture of the product [9], or stimulating haptic imagery [23]. Non-haptic compensation tactics include quality cues like brand name and price [24], risk reliever cues like return policies [25], or managing situational moderating factors like consumer mood or product expertise [14]. Other signaling cues like corporate credibility, retailer reputation and online product reviews made by other consumers have strong impact on the perception of the quality of the product and perception of risk [26].

The lack of touch becomes even a greater barrier during the purchase stage, when haptic information facilitates evaluation. Lester et al. [27] found that one of the five most important reasons for not purchasing online was an inability to touch the merchandise. At the purchase stage, a decision is made and the transaction is completed. As consumers move on to the purchase stage, they will be less focused on information gathering with respect to product attributes and more focused on evaluating how the various alternatives may satisfy their shopping goals $[27,28]$.

When purchasing, risk emerges from the difficulty in establishing a correct evaluation of the product and its benefits. If online apparel consumers have not direct experience of the product, the perceived product performance risk increases due to the inability to gauge the dominant attributes of the product such as its texture, weight, or roughness [29-31]. At this point, even compensational strategies, such as virtual product experience, seem unable to reduce tactile risks of product performance leading to an unwanted effect, namely that the consumer abandons the idea of making a purchase. Other signals, like third party endorsement, presence of physical stores, and product warranty are also considered [32].

According to the previous arguments, we argue that the level and 
the type of NFT associated to a consumer could influence the search and purchase behavior in the online channel. Thus, for consumers with high level of autotelic NFT, for whom touch provides pleasure and enjoyment, the lack of haptic cues will reduce the likelihood of using the online channel for search and purchase purposes.

By contrast for consumers with a high instrumental NFT, for whom touch is a mean of gathering information referred to physical, geometrical o material attributes, the internet's lack of haptic cues might be offset by the efficient, quick and convenient possibilities for comparing information during the search stage, although the lack of touch will continue to prove a barrier which is difficult to overcome when it comes to purchasing.

In light of the above we posit the following hypotheses:

At the pre-purchase stage, when searching for information:

H1a: high autotelic NFT customers will be less prone to use the online channel for search purposes than low autotelic NFT customers.

H1b: high instrumental NFT customers will be more prone to use the online channel for search purposes than low instrumental NFT customers as seen in Figure 2

We also state that for purchasing:

H2a: high autotelic NFT customers will be less prone to use the online channel for purchasing purposes than low autotelic NF customers.

H2b: high instrumental NFT customers will be less prone to use the online channel for purchasing purposes than low instrumental NFT customers.

\section{NFT and Hedonic or Utilitarian shopping orientation}

Hedonic and utilitarian orientations have been studied extensively in the literature on shopping behavior [16]. Hedonic shopping focuses on stirring emotions and is driven by fun, entertainment and enjoyment in itself regardless of whether a purchase is planned or made [33-35]. Hedonic shopping orientation has traditionally been associated with brick-and-mortar retailers due to their socially visible nature, making consumers perceive them as places to have an enjoyable sensorial experience [36].

Utilitarian shopping is primarily rational and cognitive in nature and is linked to factors concerning purchase efficiency and is aimed at accomplishing a task or meeting a specific set of objectives $[16,37,38]$. Utilitarian shopping orientation tends to be associated to the online channel (e.g. by minimizing the time for browsing, saving preferences and comparing products) [39]. When consumers shop out of need, they actively search efficiently for information, especially given that comparisons are much faster and easier online than offline [11].

As for satisfying hedonic motives, consumers will use subjective and emotional information to choose between alternative products, they might also score high on the autotelic dimension of NFT [7,11]. Thus, the hedonic shopping orientation, based on shopping for fun, might moderate the effect of autotelic NFT on the likelihood of searching and purchasing online, since autotelic NFT involves emotional arousal.

As for satisfying utilitarian motives, consumers will use objective, tangible information when making a choice, they might also score high on the instrumental dimension of need for touch $[7,11]$. Thus, the utilitarian shopping orientation, based on shopping for efficiency, might moderate the effect of instrumental NFT on the likelihood of searching and purchasing online, since instrumental NFT involves task accomplishment.

Given the above, the following hypotheses were established:

During the search stage:

H3a: Hedonic shopping orientation will moderate the relationship between autotelic NFT and the likelihood of using online channels for search purposes.

H3b: Utilitarian shopping orientation will moderate the relationship between instrumental NFT and the likelihood of using online channels for search purposes.

During the purchasing stage:

H4a: Hedonic shopping orientation will moderate the relationship between autotelic NFT and the likelihood of using online channels for purchasing purposes.

H4b: Utilitarian shopping orientation will moderate the relationship between instrumental NFT and the likelihood of using online channels for purchasing purposes (Figure 3).

\section{Research Methods}

\section{Survey}

A self-reported questionnaire was conducted in order to measure the following three concepts: need for touch (NFT), shopping orientation, and online preferences when searching for information and purchasing. The chosen product category was mass market apparel. As already stated, this product category has a relevant tactile sensory component $[2,3]$ as well as strong utilitarian and hedonic components [17].

To measure NFT, participants indicated the degree to which they agreed or disagreed with each of the 12 items on the NFT scale developed by Peck and Childers [4] on a 7-point Likert scale, scored from 1 (completely disagree) to 7 (completely agree). Six items referred to the autotelic dimension (A), and six to the instrumental dimension (I). Items were randomly ordered.

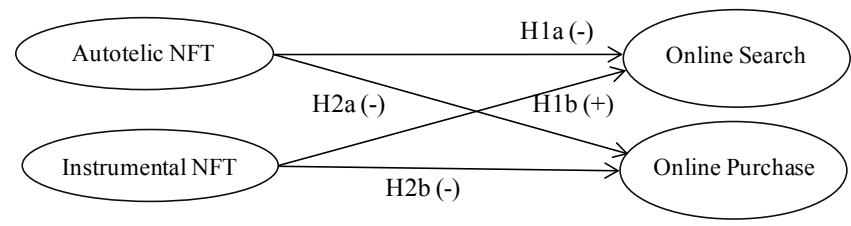

Figure 2: Theoretical model of the study; Hyphoteses 1 and 2.

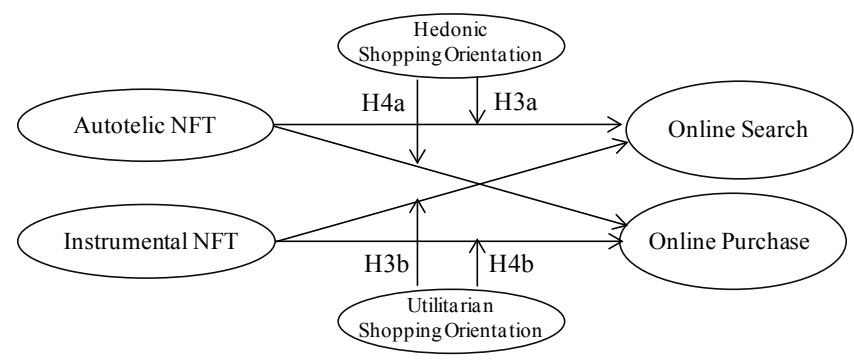

Figure 3: Theoretical model of the study; Hyphoteses 3 and 4. 
Shopping orientation was assessed via the typology developed by Westbrook and Black [40]. Four 7-point Likert scale items were used to measure utilitarian shopping orientation and four to measure hedonic shopping orientation.

Online channel preferences were assessed by two questions dealing with respondent habits in the apparel search and purchase stages. A 5-point Likert scale with items ranging from "always search/buy online" to "always search/buy in physical shop" adapted from Spears and Singh [41] was used. Data concerning frequency of online searching and online purchasing for apparel were also gathered from respondents. The questionnaire was examined by a panel of experts to evaluate content validity and to ensure the accuracy of the text translations. To verify the clarity of the questions and gain feedback on the length of the questionnaire, it was further tested on a group of 25 students prior to definitive data collection.

\section{Data collection}

A sample of 256 Spanish college students, aged between 18 and 22 , was recruited to participate in the survey. A total of 227 completed the survey and were therefore used in the study. Respondents took an average of approximately 13 minutes to complete the survey. College students are a representative target for this study, since they are more likely to use internet when shopping for clothing. This target group is also technology savvy and represents the first online shopper generation that adapts easily to innovations and to new product visualization technology. Youngsters between 18 and 22 are avid followers of style trends and seek enjoyment and hedonic experiences when browsing the Internet for fashion clothing [42].

\section{Respondent demographics}

Respondents' demographics? (gender, habits and shopper profile) are listed in Table 1.

\section{Results}

The 12 items of the NFT scale and the 8 items of the Shopping Orientation scales were subjected to principal component analysis [PCA]. The suitability of the data for factor analysis was assessed. The KMO value was 0.92 , and Bartlett's Test of Sphericity reached statistical significance, supporting the factorability of the correlation matrix. The number of extracted factors with eigenvalues equal to or greater than 1 was four [two dimensions of NFT and two of Shopping Orientation]. All items were assessed on the appropriate factor and factor loadings were higher than 0.6 .

Then, a four-factor confirmatory factor analysis (CFA) was performed to assess the psychometric properties and discriminant validity of all measures. The measurement model achieved acceptable fit as indicated by a Comparative Fit Index (CFI) of 0.936 and a Root Mean Square Error of Approximation (RMSEA) of 0.057.

To assess discriminant validity, the Fornell and Larcker [43] test was conducted. Average Variance Extracted estimates ranged from 0.73 to 0.81 and were all greater than the square correlation between constructs. Reliability was measured with Cronbach's alpha and exceeded the generally accepted minimum level of 0.60 (Nunnally). Autotelic NFT (alpha value $=0.912$ ), instrumental NFT (alpha value $=0.888$ ), utilitarian shopping orientation (alpha value $=0.902)$ and hedonic shopping orientation (alpha value $=0.906$ ).

With all exploratory diagnostics exceeding the suggested thresholds, the scales were summed and averaged separately to form independent indices of autotelic NFT, instrumental NFT, hedonic shopping orientation and instrumental shopping orientation to be used in further analysis.

Hypotheses 1a and $1 \mathrm{~b}$ established the relationship between the autotelic and instrumental NFT level and online search, whereas hypotheses $2 \mathrm{a}$ and $2 \mathrm{~b}$ established the relationship between the autotelic and instrumental NFT level and online purchase.

A median split was used to categorize respondents into high- and low- autotelic NFT $(\mathrm{Me}=5)$ and instrumental NFT $(\mathrm{Me}=4.7)$

A MANOVA was run with autotelic NFT and instrumental NFT as the independent variables. Online search and online purchases were dependent variables.

This multivariate test revealed a significant effect of autotelic NFT (Wilk's $\lambda=0.954 ; \mathrm{F}=5.277 ; \mathrm{p}<0.01$ ) and of instrumental NFT (Wilk's $\lambda=0.971 ; \mathrm{F}=3.324 ; \mathrm{p}<0.01)$.

The result of the between-subjects effect did not show a significant difference in online search due to consumers autotelic NFT $(F(1,220)=$ $1.196, \mathrm{p}>0.05)$ nor instrumental NFT $(\mathrm{F}(1,220)=.466, \mathrm{p}>0.05)$. Thus, hypotheses H1a and H1b could not, therefore, be supported.

On the other hand, the result of the between-subjects effect shows a significant impact of consumers autotelic NFT on the likelihood of online purchase $(\mathrm{F}=8.789, \mathrm{p}<0.01)$ and instrumental NFT on online purchase $(\mathrm{F}=5.134, \mathrm{p}<0.05)$. As shown in Table 2, the mean differences between low and high autotelic NFT $[\mathrm{F}[1,220]=8.789, \mathrm{p}<0.01]$ and low and high instrumental NFT $(\mathrm{F}(1,220)=5.134, \mathrm{p}<0.05)$ in online purchase do prove significant, thus supporting $\mathrm{H} 2 \mathrm{a}$ and $\mathrm{H} 2 \mathrm{~b}$.

The moderator hypothesis conjectured that consumer's shopping orientation-hedonic and utilitarian- will interact in the relationship between autotelic NFT and instrumental NFT and online search and purchase.

A median split was used to categorize respondents into high- and low- hedonic and utilitarian groups. Thus a MANOVA was conducted to test the moderating effect of interaction between autotelic NFT and hedonic orientations and instrumental NFT and utilitarian orientations

\begin{tabular}{|c|c|}
\hline Gender & Percentage \\
\hline Male & $39.20 \%$ \\
\hline Female & $60.80 \%$ \\
\hline Frequency of internet use & \\
\hline Several times a day & $90.70 \%$ \\
\hline Once a day & $5.30 \%$ \\
\hline Several times a week & $3.10 \%$ \\
\hline Less than once a week & $0.90 \%$ \\
\hline Mean no. of fashion products bought (last 12 months) & 17.39 items \\
\hline Mean no. internet searches for fashion (last 12 months) & 36.03 times \\
\hline Mean time (in years) as internet user & 9.2 years \\
\hline Mean time (in hours per week) spent online & 18.7 hours/week \\
\hline
\end{tabular}

Table 1: Descriptive Statistics from the data set $(\mathrm{N}=227)$.

\begin{tabular}{|c|c|c|c|c|}
\hline & \multicolumn{2}{|c|}{ Autotelic NFT } & \multicolumn{2}{c|}{ Instrumental NFT } \\
\hline \multirow{2}{*}{$\begin{array}{c}\text { Online } \\
\text { purchase }\end{array}$} & $\begin{array}{c}\text { Low autotelic } \\
\text { NFT }\end{array}$ & $\begin{array}{c}\text { High autotelic } \\
\text { NFT }\end{array}$ & $\begin{array}{c}\text { Low instrumental } \\
\text { NFT }\end{array}$ & $\begin{array}{c}\text { High instrumental } \\
\text { NFT }\end{array}$ \\
\cline { 2 - 5 } & 3.526 & 2.783 & 3.432 & 2.877 \\
\hline
\end{tabular}

Table 2: Means for effect of autotelic NFT and instrumental NFT on online purchase. 
as independent variables on both online search and online purchases as dependent variables.

As indicated in the Table 3 as per the results of the MANOVA, the effect of the autotelic NFT did not seem to be moderated by the effect of the hedonic orientation, either in online search or in online purchase. Hypotheses $\mathrm{H} 3 \mathrm{a}$ and $\mathrm{H} 4 \mathrm{a}$ could not, therefore, be supported.

Instrumental NFT was found to be moderated by the effects of utilitarian orientation in both online search $(\mathrm{F}(2,220)=3.174, \mathrm{p}<0.05)$ and online purchase $(\mathrm{F}(2,220)=4.221, \mathrm{p}<0.05)$.

In the high utilitarian condition, online search for low instrumental NFT $(M=3.556)$ and high instrumental NFT $(M=3.548)$ subjects did not differ significantly $(\mathrm{F}(1,120)=.191, \mathrm{p}>0.05)$. In the low utilitarian condition, however, the likelihood of online search in low instrumental NFT $(M=3.158)$ subjects was significantly higher $(F(1,103)=3.248$, $\mathrm{p}<0.05)$ than that of high instrumental NFT $(\mathrm{M}=2.824)$ subjects.

Regarding purchasing, subjects with low instrumental NFT (M $=3.796$ ) were more prone to online purchases if they scored high on utilitarian orientation $(\mathrm{F}(1,120)=7.012, \mathrm{p}<0.01)$ compared to those with low instrumental NFT $(\mathrm{M}=3.068)$ in low utilitarian conditions $(\mathrm{F}(1,103)=10.247, \mathrm{p}<0.01)$.

Hence, these results support $\mathrm{H} 3 \mathrm{~b}$ and $\mathrm{H} 4 \mathrm{~b}$, as shown in Figure 4.

\section{Discussion, Implications and Future Research Lines}

\section{Discussion}

The goals of the current research were firstly to examine the influence of both dimensions of NFT (autotelic NFT and instrumental NFT) on two different stages of the online apparel purchase decision process, namely information search and purchase, and secondly to study the moderating effect of the hedonic and utilitarian shopping orientations on the mentioned relationships.

Apparel is considered a category where haptic perception plays an important role in evaluating a product's properties given that the dominant attribute of such a category is texture, which conveys qualities such as softness, warmth or flexibility [7]. Thus, the Internet is still a challenging distribution channel for the apparel category, which entails a strong need for products to be seen, felt, touched [2] and tried on.

Based on the findings of this research, the first point to highlight is the significant and negative influence of autotelic NFT and instrumental

\begin{tabular}{|c|c|c|c|c|c|c|}
\hline & \multicolumn{2}{|c|}{ MANOVA } & \multicolumn{5}{c|}{ ANOVA F-Values } \\
\hline Main Effects & Wilks & F-Value & df & Online search & df & $\begin{array}{c}\text { Online } \\
\text { purchase }\end{array}$ \\
\hline Autotelic NFT & 0.954 & $5.277^{\mathrm{a}}$ & 1 & 1.196 & 1 & $8.789^{\mathrm{a}}$ \\
\hline Instrumental NFT & 0.971 & $3.324^{\mathrm{a}}$ & 1 & 0.466 & 1 & $5.134^{\mathrm{b}}$ \\
\hline \multicolumn{7}{|c|}{ Interactions } \\
\hline $\begin{array}{c}\text { Autotelic NFT } \\
\times \text { Hedonic } \\
\text { Orientation }\end{array}$ & 0.988 & 0.665 & 2 & 0.498 & 2 & 0.904 \\
\hline $\begin{array}{c}\text { Instrumental } \\
\text { NFT } \times \text { Utilitarian } \\
\text { Orientation }\end{array}$ & 0.953 & 2.659 & 2 & $3.174^{\mathrm{b}}$ & 2 & $4.221^{\mathrm{b}}$ \\
\hline
\end{tabular}

${ }^{a} p<0.01$

${ }^{b} p<0.05$

Table 3: Effects of autotelic and instrumental NFT, and interaction autotelic NFT* hedonic orientation and instrumental NFT*utilitarian orientation on online search and online purchase.
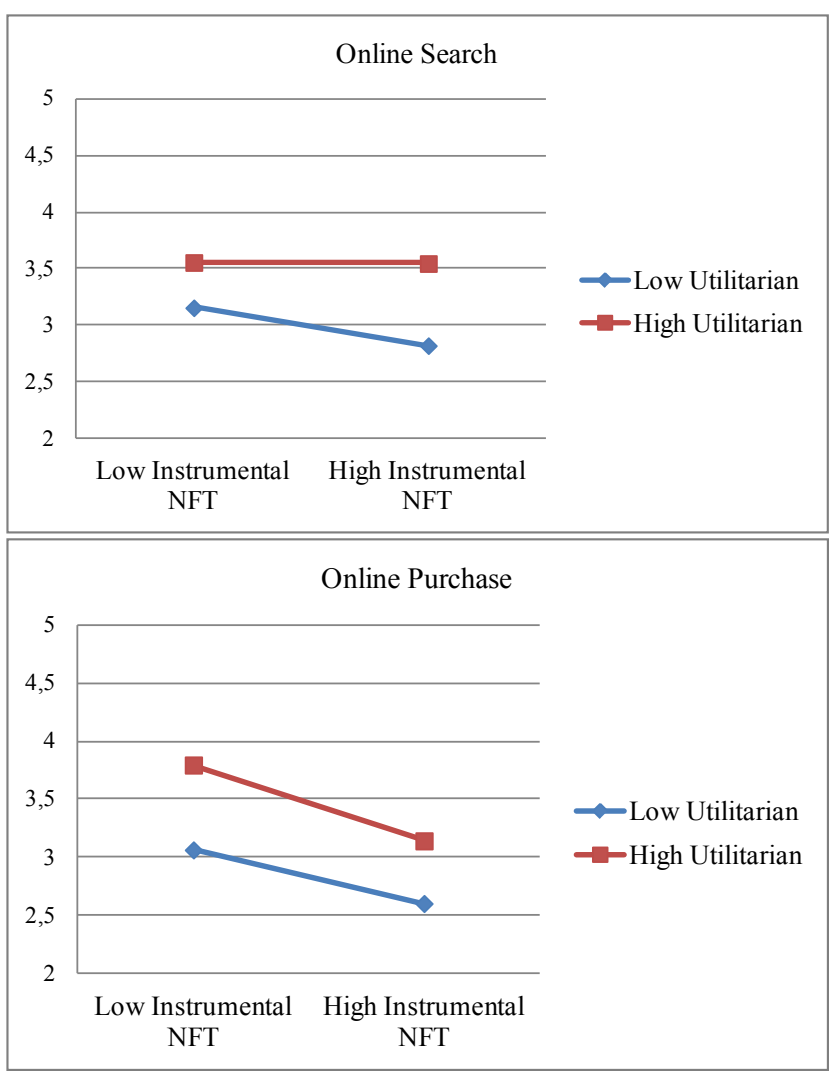

Figure 4: Effects of interaction between instrumental NFT and consumer's utilitarian orientation on online search and online purchase.

NFT consumer levels on the likelihood of purchasing apparel online. Conversely, we found no significant influence in the relationship between autotelic NFT and instrumental NFT consumer levels and the likelihood of using online channels to search for information.

These results suggest that in the apparel category the lack of haptic cues remains a problem in the purchase stage for subjects who need to touch merely for pleasure (high autotelic)as well as those for whom touch provides a source of information (high instrumental). However it does not seem to be a problem at the search stage for high instrumental consumers, as they can have $24 / 7$ easy and convenient accessibility to product features information $[18,19]$.

Moreover, results show that the utilitarian orientation moderates the relationship between the instrumental NFT dimension and the use of online channels for search and purchase purposes.

During the search stage, buyers with a strong utilitarian orientation are equally likely to engage in the use of online channels to obtain information, regardless of their level of instrumental NFT. As posited by other authors [35], utilitarian orientation encourages efficient allocation of resources when purchasing, the online channel proving perfectly capable of satisfying this need despite its haptic limitations. This conclusion is even more relevant in the light of the results obtained by Watchravesringkan and Shim [44] showing that the search intention has proved to be the most important antecedent variable of purchase intention for apparel. 


\section{Managerial implications}

The implications of these results for pure online retailer's strategy are of great interest. They show the high importance of introducing incentives to buy for consumers in the search mode as a way to overcome the risk they will perceive at the purchase stage. Those incentives might be targeted to promote the purchase or just to reassure consumers that the return of the merchandise will be fully accepted should the consumer not be satisfied with the product purchased. Promotions to motivate the sale might include classical monetary/non-monetary promotions as well as the possibility to send samples of textiles to consumers to compensate their NFT.

Despite the findings that emerge from the present research may be of use to all kinds of online retailers, they prove particularly relevant in the case of pure players -such as Buyvip, Amazon, or Zapposwho are only available online and who are therefore incapable of surmounting the difficulties inherent in this channel compared to the onsite experience of brick-and-mortars. It is these outlets on whom the conclusions to emerge focus in particular.

Strategies aimed at overcoming the lack of haptic information in the online channel might also include providing autotelic information concerning the product- e.g. whether it is soft- and enhancing the online channel shopping experience. Developing online communications focusing on the physical elements of the product, like size, form, material or color $[6,9,23]$, linked to action taken on the brand attributes to offset the risk of the online medium [24,25] may make up for the lack of product accessibility for consumers with high NFT in its instrumental dimension. Such risk compensating communication regarding product information related to tactile and trial attributes might be both visual and verbal, and address aspects like touch, feel, fit, comfort or appearance [10].

\section{Future research}

This work opens up a number of future avenues that merit inquiry. One line of research should focus on exploring autotelic and instrumental NFT in multichannel purchase strategies. Linked directly to the latter, it would no doubt prove interesting to delve more deeply into the role of other moderating variables such as brand awareness and previous brand consumption. A second area of inquiry would be to explore in greater depth the impact of autotelic NFT, given that the present research has failed to provide the expected outcomes with regard to this dimension. Finally, it would also seem appropriate to extend the analysis of the limitations of the online channel to other product categories of a different nature such as electronic items, which are able to arouse an instrumental need, yet which involve a less important hedonic component.

The current research is not without its limitations, amongst which we highlight the need to work with data self-reported by consumers. Nevertheless, questions concerning frequency of Internet use and online purchases have been included in an effort to place those surveyed within in their actual situation.

\section{References}

1. EMarketer (2014) Worldwide B2C Ecommerce: 2013 Forecast and Comparative Estimates.

2. Citrin AV, Stem DE, Spangenberg ER, Clark MJ (2003) Consumer need for tactile input: an internet retailing challenge. Journal of Business Research 56: 915-922.

3. Grohmann B, Spangenberg ER, Sprott DE (2007) The influence of tactile input on the evaluation of retail product offerings. Journal of Retailing 83: 237-245.
4. Peck J, Childers T (2003) Individual differences in haptic information processing: the "Need for Touch" scale. Journal of Consumer Research 30: 430-442.

5. Klatzky RL, Lederman SJ, Matula DE (1993) Haptic exploration in the presence of vision. Journal of Experimental Psychology: Human Perception and Performance 19: 726-743.

6. McCabe DB, Nowlis SM (2003) The effect of examining actual products or products description on consumer preference. Journal of Consumer Psychology 13: 431- 439

7. Workman JE (2010) Fashion consumer groups, gender, and need for touch Clothing \& Textile Research Journal 28: 126-139.

8. Schifferstein HNJ, Spence C (2007) Product Experience, (1 ${ }^{\text {st }}$ edtn), Elsevier, Amsterdam pp: 133-161.

9. Peck J, Childers T (2003) To have and to hold: the influence of haptic information on product judgments. Journal of Marketing 67: 35-48.

10. Yu UJ, Lee HH, Damhorst ML (2012) Exploring multidimensions of product performance risk in the online apparel shopping context: visual, tactile, and trial risks, Clothing and Textiles Research Journal 30: 251-266.

11. Peck J, Wiggins J (2006) It Just Feels Good: Customers' Affective Response to Touch and Its Influence on Persuasion. Journal of Marketing 70: 56-69.

12. (2009) Euromonitor International.

13. Bloch PH, Bruce GD (1984) Product involvement as leisure behavior. Advances in Consumer Research 11: 197-202.

14. Yazdanparast A, Spears N (2013) Can consumers forgo the Need to Touch products?: An investigation of nonhaptic situational factors in an online context. Psychology \& Marketing 30: 46-61.

15. Shim S, Eastlick MA, Lotz SL, Warrington P (2001) An online prepurchase intentions model: The role of intention to search. Journal of Retailing Best Overall Paper Award- The Sixth Triennial AMS/ACRA Retailing Conference 77: 397-416.

16. Babin BJ, Darden WR, Griffin M (1994) Work and/or fun: measuring hedonic and utilitarian shopping value. Journal of Consumer Research 20: 644-656.

17. Voss KE, Spangenberg ER, Grohmann B (2003) Measuring the hedonic and utilitarian dimensions of consumer attitude. Journal of Marketing Research 40 310-320.

18. Sands S, Ferraro C, Luxton S (2010) Does the online channel pay? A comparison of online versus offline information search on physical store spend. The International Review of Retail, Distribution and Consumer Research 20 : 397-410.

19. Zhang J, Farris PW, Irvin JW, Kushwaha T, Steenburgh TJ, et al. (2010) Crafting integrated multichannel retailing strategies. Journal of Interactive Marketing 24: 168-180.

20. Retail 2014: The anytime anywhere universe, PWC.

21. Frambach RT, Roest HC, Krishnan TV (2007) The impact of consumer internet experience on channel preference and usage intentions across the different stages of the buying process. Journal of Interactive Marketing 21: 26-41.

22. Payne JW, Bettman JR, Johnson EJ (1993) The adaptive decision maker Cambridge, UK: Cambridge University Press.

23. Peck J, Barger V, Webb A (2012) In search of a surrogate for touch: the effect of haptic imagery on perceived ownership. Journal of Consumer Psychology 23: 189-196.

24. Olson JC, Jacoby J (1972) Cue utilization in the quality perception process. Association for Consumer Research 2: 167-179.

25. Kirmani A, Rao AR (2000) No pain, no gain: a critical review of the literature on signaling unobservable product quality. Journal of Marketing 64: 66-79.

26. Aldás MJ, Currás PR, Sanz BS (2011) Online information quality as determinant of perceived risk reduction in e-commerce: an application to apparel virtual stores. Int. J. of Internet Marketing and Advertising 6: 352-372.

27. Lester DH, Forman AM, Loyd D (2006) Internet shopping and buying behavio of college students. Services Marketing Quarterly 27: 123-138.

28. Huneke ME, Cole C, Levin IP (2004) How varying levels of knowledge and motivation affect search and confidence during consideration and choice. Marketing Letters 15: 67-79. 
Citation: Manzano R, Gavilan D, Ferrán M, Avello M, Abril C (2016) Autotelic and Instrumental Need for Touch: Searching for and Purchasing Apparel Online. Int J Econ Manag Sci 5: 322. doi:10.4172/2162-6359.1000322

29. Choi J, Lee KH (2003) Risk perception and e-shopping: a cross-cultural study. Journal of Fashion Marketing and Management 7: 49-64.

30. Forsythe S, Liu C, Shannon D, Gardner LC (2006) Development of a scale to measure the perceived benefits and risks of online shopping. Journal of Interactive Marketing 20: 55-75

31. Rosa JA, Garbarino EC, Malter AJ (2006) Keeping the body in mind: the influence of body esteem and body boundary aberration on consumer beliefs and purchase intentions. Journal of Consumer Psychology 16: 79-91.

32. HsiuJu R (2006) Risk-reducing signals for new online retailers: a study of single and multiple signalling effects. Int $\mathrm{J}$ of Internet Marketing and Advertising 3: 299-317.

33. Holbrook MB, Hirschman EC (1982) The experiential aspects of consumption: consumer fantasies, feelings, \& fun. Journal of Consumer Research 9: 132 139.

34. Arnold MJ, Reynolds KE (2003) Hedonic shopping motivations. Journal of Retailing 79: 77-95.

35. Childers TL, Carr CL, Peck J, Carson S (2001) Hedonic and utilitarian motivations for online retail shopping behavior. Journal of Retailing 77: 511535.
36. Dholakia RR, Zhao M, Dholakia N (2005) Multichannel retailing: a case study of early experiences. Journal of Interactive Marketing 19: 63-74.

37. Hirschman EC, Holbrook MB (1982) Hedonic consumption: emerging concepts, methods and propositions. The Journal of Marketing 46: 92-101.

38. Batra R, Ahtola OT (1991) Measuring the hedonic and utilitarian sources of consumer attitudes. Marketing Letters 2: 159-170.

39. Wolfinbarger M, Gilly MC (2001) Shopping online for freedom, control, and fun California Management Review 43: 34-55.

40. Westbrook RA, Black W (1985) A motivation-based shopper typology. Journal of Retailing 61: 78-103.

41. Spears N, Singh SN (2004) Measuring attitude toward the brand and purchase intentions. Journal of Current Issues \& Research in Advertising 26: 53-66.

42. Dennis C, Fenech T, Merrilees B (2004) E-Retailing, Routledge.

43. Fornell C, Lacker CF (1981) Evaluating structural equations models with unobservable variables and measurement error. Journal of Marketing Research 18: $39-50$.

44. Watchravesringkan K, Shim S (2003) Information search and shopping intentions through Internet for apparel products. Clothing and Textiles Research Journal 21: 1-7. 